\title{
DEVELOPMENT OF SMART APPLICATIONS FOR COASTAL EROSION AND LANDSLIDE RISK REDUCTION Francesco Castelli ${ }^{1}$, Martina Greco ${ }^{2^{*}}$ \\ 1,2* Faculty of Engineering \& Architecture, University of Enna "Kore”, Italy. Email: ${ }^{1}$ francesco.castelli@unikore.it, ${ }^{2 *}$ martina.greco@unikore.it
}

\author{
Article History: Received on $16^{\text {th }}$ May 2020, Revised on $15^{\text {th }}$ August 2020, Published on $26^{\text {th }}$ September 2020
}

\begin{abstract}
Purpose: Cloud computing has opened new opportunities in disastrous natural early warning. The scientific community has recognized the significance of the geo-analytic approach in complex decision-making processes for critical situations due to natural events such as coastal erosion and landslides. The paper describes the progress in the development of ITC dissemination systems for the population to promote the preparedness toward the coastal risk.
\end{abstract}

Methodology: To achieve these goals an information system based on an Open Source Cloud Computing platform following a PaaS (Platform as a Service) and SaaS (Software as a Service) approaches has been used.

Main Findings: The southern coast of Sicily (Italy) and the islands of the archipelagos of Malta are highly exposed to risks coming from the sea. Such coasts are subjected to fast erosion due to natural and anthropic causes which involve the failure of cliffs, the triggering of localized erosions, and the possibility of flooding.

Implications/Applications: The research effort aims to build an interconnected framework through the implementation of smart technology, which involves surveillance, early warning, and reduction of coastal threats, with a specific goal to educate citizens regarding flood hazards, coastal waters, and degradation, cliff collapses and safety steps.

Novelty/Originality of this study: The study expresses a different perspective on cloud computing to prevent the effects of disastrous natural events and to provide indications of areas susceptible to risk.

Keywords: Coastal Erosion, Landslide, Early Warning System, Smart Technologies, ITC Dissemination.

\section{INTRODUCTION}

The southern coast of Sicily (Italy) and the islands of Malta's archipelagos are highly exposed to risks coming from the sea. These coasts are subjected to fast erosion due to natural causes which involve the failure of cliffs (Young et al., 2016; Sunamura, 2018; Young \& Carilli, 2018), the triggering of localized erosions (Alessio \& Keller, 2019; Yusuf et al., 2017), and the possibility of flooding.

In this market, several countries have already made strides in the implementation of urban and population growth management procedures and even in mitigating related risks. The approaches are focused upon danger and risk zoning, which can nevertheless entail difficulties owing to the technology as well as socio-economic considerations involved (Castelli et al. 2016a; Castelli et al. 2016b; Cavallaro et al. 2018). The NEWS analysis plan "Nearshore threat monitoring and Early Warning Network" (INTERREG V-A Program "Italy-Malta" 2014-2020) seeks to gain local awareness through the implementation of smart technology in matters affecting coastal erosion and early warning threats.

It intends to establish an interconnected network including detection, early alert, and coastal hazards reduction (Figure 1) to educate the public on the dangers of floods and coastal sand erosions as well as cliff collapses (Alejano et al., 2013; Barlow et al., 2017; Benumof et al., 2000; Bezerra et al., 2011; Budetta et al., 2000; Caloiero et al., 2019; Canora et al., 2012; Fazio et al., 2019) and at activating protection measures in order to avoid damages to persons. Enhancing both remote sensing as well as data processing technologies does not compromise field research and professional judgment as a consistent usage of event resources, the primary input criterion for risk management and evaluation, cannot be established using automated data collection technology alone.

The research activity has the purpose to develop socio-cognitive models and support tools on the theme of the safety of territory. The trust attitudes are essential to ensure efficacy and efficiency of prevention. The aim is to individuate what factors are favorable and unfavorable for the prevention both at the individual-cognitive level and in terms of social and collective dynamics.

Warning models will compensate for several risk variables, varying activation levels, and multiple response typologies for all parties concerned. This does not only include citizens' trust in institutions (i.e., their faith in the preventive structure) but also their trust in citizens' institutions (as a source of information). Then study has been focused on how people perceive disasters and risks by tools, specifically built and pre-tested, or taken from the literature, to measure self-efficacy, control, and trust. Data collected are put in relation with psychosocial characteristics of people: this allows, to identify socio and demographic profiles of people who perceive and represent disasters - and related risk - in different ways. By the results of the study, it will be possible to define the instruments to support interventions: promotion of bi-directional communication among decision-makers, technicians, volunteers, and population, with the 
aim to improve mutual trust.

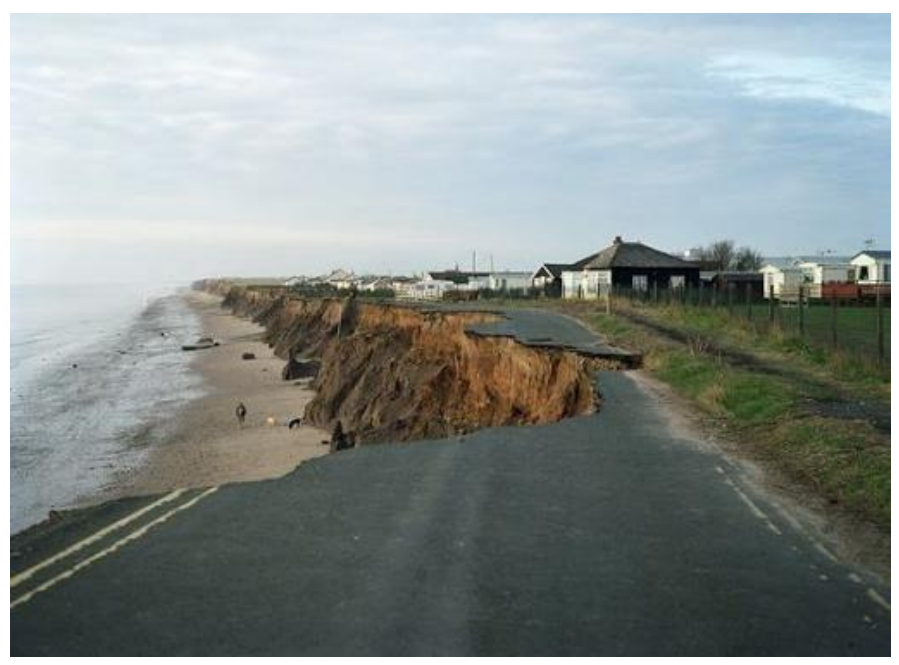

Figure 1: Coastal erosion and landslide

Source: Meteoweb

\section{LITERATURE REVIEW}

In the last two decades, the most significant contributions in the field of trust models for socio-technical systems, come from logical and formal approaches (Hironori et al., 2016), computational approaches (Chatzipavlis et al., 2019; Jia et al., 2017), and finally, socio-cognitive approaches (Butt et al., 2016; Gariano \& Guzzetti, 2016).

These three lines of research often overlap, but differ for their aims: logical approaches use mathematical logic to analyze and implement trust relationships (Figure 2). Computational approaches use trust models in automatic systems, independently for the representative structure. Finally, socio-cognitive approaches consider trust as a mental attitude, strongly dependent on the social context.

In the proposed study computational and formal models of individual and collective behavioral dynamics of stakeholders exposed to risk have been developed.

A variety of variables complicates the efficient management of trust attitudes in the light of natural disasters: quantity, variability, and sophistication of the stakeholders involved (personal and group, public and private, natural and artificial), behavior, and experiences, sometimes without planning.

A detailed study and integration of these variables enable the creation and preparation of preventive rules for an accurate and reliable strategy, applying them to specific circumstances and risk typologies (Castelli et al., 2017; Foti et al., 2020; Iannucci et al., 2018; Pomaro et al., 2017).

For prevention, a central role is played both by the context in which the alert is produced that by the know-how previously accumulated through assimilation of the relevant prevention rules and their perceived trustworthiness. In the intervention phase, there is a need for active participation of multiple subjects to a concerted effort, under high levels of stress: thus it is essential to model trust factors focused on interaction and cooperation between subjects (Ahmed et al., 2020; Bilello et al., 2016; Castelli et al., 2008). The effectiveness of response approaches during a natural catastrophe relies heavily on delegated action by delegations of stakeholders that are willing, on the basis of their well-tested and generally recognized expertise, of guarantee full legitimacy. This confidence capacity has to be built prior to an action, however, it reveals the interest through this crisis, which, if it is effective, may inevitably further improve the perceived competence of the respective actors (Castelli \& Motta, 2013; Castelli \& Greco, 2018).

The emergency response includes many criticality considerations, such as the human element (panic reaction, large casualty numbers, possible rescue hurdles), geographical aspects (presence of evacuation routes, adverse weather hazards, quick access to or from the region concerned), and preparation of the operation itself (independent organizations which use different techniques).

Moreover, the way in which the emergence is managed can bring further difficulties.

Usually, the interventions are coordinated at the top level, are based on strict procedures, and not always consistent with one another, especially if the actors in the field are heterogeneous.

The research aims to create a simulation model of the critical situation, in which the involved actors are represented (citizens, rescuers, institutional subjects), giving attention to cognitive aspects, that is to the way actors make decisions, find out criticalities, communicate and coordinate with other relevant actors and with the environment. Such model has 
been then implemented in a software tool, that is a simulation platform, through which it is possible to understand the dynamics of the interaction among the environment and the involved actors, comparing different strategies of emergency management and performing analyses aiming at finding out strong points and criticalities in the management, starting from the reference context. The results will be then used to give indications to the intervention agencies, but also to contribute to the creation of informative material for the population to be used in case of emergency.

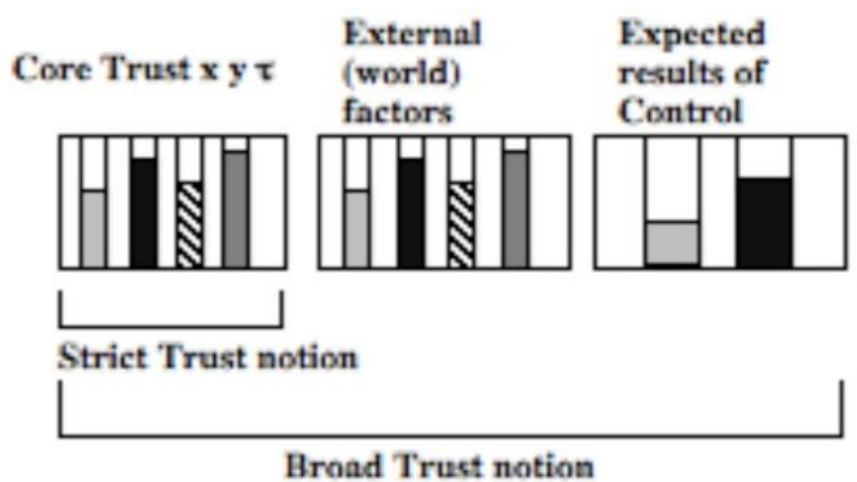

Figure 2: Trust, autonomy, and control: A relationship

Source: Falcone et al. (2003)

\section{METHODOLOGY}

The study aims to develop early warning systems to enable civil defense (evacuations, road closures, etc.) in emergency circumstances and to develop detection and control systems to identify areas of danger.

To achieve this goal an information system is based on an Open Source Cloud Computing (Adhikari \& Srirama, 2019; Babu \& Venkata, 2013; Kumar \& Sharma, 2017) platform following a PaaS (Platform as a Service) and SaaS (Software as a Service) approaches has been used (Figure 3). In this case, the SaaS services are devoted to the evaluation of risk and active people participation in monitoring and preventing hydro-geological risk (Hooke, 1998) by the modeling and simulation of social dynamics in the prevention and management of emergencies.

To assess the risk it is necessary to analyze the evolution of coastal erosion and landslides (Fazio et al., 2019); to identifying correlations between piezometric levels, rainfall and landslide displacements, movements after intense rainfalls (Butt et al., 2016; Gariano \& Guzzetti, 2016) and to obtain indications of potential risk areas. This requires knowledge of landslide intensity and return period, evaluation of hazard, prediction of time-evolving phenomena, and vulnerability level in urban areas_(Castelli \& Maugeri, 2013; Castelli et al., 2018; Castelli et al., 2016c).

\section{RESULTS AND DISCUSSION}

\section{Computing Systems for Alert and Emergency Management}

The Paas Service consists in implementing a GIS platform that allows the adoption of analysis techniques that could not be otherwise introduced, thanks to the ability to perform calculations on a large number of parameters, with the possibility to overlap and cross-referencing spatial data. This task aims to expand the potential of traditional GIS, creating a horizontal platform, that allows the simultaneous management of both data from consolidated databases, and data from the monitoring network. The information stored in the GIS will be exposed through open services.

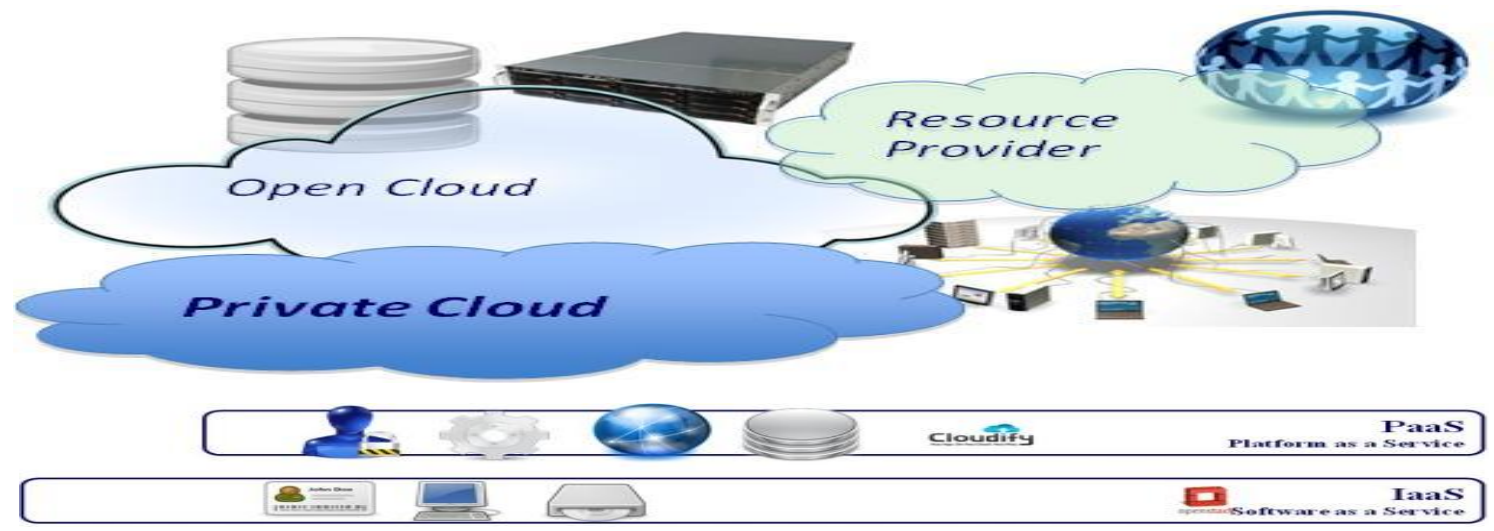

Figure 3: Open source cloud computing platform

Source: Own illustration (created by author) 
The simulation models for the study of scenarios of interactions, both during risk prevention and management of emergencies, are translated into complex software components, due to factors inherent in the complexity of the models and the dynamics of interaction among various parameters involved. In particular, the study is devoted to:

- Analysis of predictive models of natural hazards, process characterization and identification;

- Involved analysis of risk scenarios;

- For each risk scenario identification of patterns, elements that characterize it;

- Design and implementation of a test-bed based on the model simulation.

\section{Smart Applications for Risk Governance Social Models}

Integration, connectivity, and interoperability between data sources play a key role during the early stage of disaster recognition and response. The main objective of this part of the study is to investigate the individual and collective cognition during emergency and disaster management, with the aim to handle rescue operations, related to critical infrastructure, to characterize the dynamic and the interaction of all subjects involved in the emergency.

An application for local authorities has been implemented, by which institutional operators can:

- Classify, evaluate, predict hazard and estimate vulnerability during risk assessment processes;

- Manage the tools for modeling, simulation, and participation of the smart community;

- Access to GIS maps, to monitored and forecast information, simulate natural and social scenarios;

- Access to specific decision support functionalities, for the effective administration of interchanges during the caution and crisis stages.

In this context, informative applications based on real-time risk maps, to form a set of advanced systems to support citizens and technicians in alert and emergency, for risk prevention and/or emergency management have been developed (Castelli \& Lentini, 2019a; Castelli \& Lentini, 2019b). The application is an advanced system that combines weather forecasts with the probable impacts on the territory, providing a forecast of the risk of occurrence of certain phenomena (Figure 4) and providing warnings and advice on roads practicability and on staying in specific areas.

Participative applications by social networks allow interacting with the community, promoting bi-directional communication between people, volunteer technicians, and decision-makers. A model of urban interconnected infrastructures (water, wastewater, and gas networks), making more reliable the integration, connectivity, and interoperability of data sources.

The surveying and mapping of technological networks (telecommunications, transportation, energy, and water supply, networked systems) is a complex process that involves several technologies in order to develop, and effectively utilize and maintain a database (Lentini et al., 2019). Different domain experts work in order to build a realistic representation of the territory and in this process, the quality of data plays a key role in order to ensure the expected results. Surveying and mapping task is carried on firstly by collecting information about technological networked systems. This task is mainly provided by field crews finding subsurface networks, figuring out the main characteristics of these networks, then hand-filling some datasheets.

The second step is the geo-referencing task. During this phase, each node of the networked system is geo-referenced using GPS or ground base instrumentations (Figure 4). The final step is the development of the Geographical Information System (GIS), representing the company's assets, in which all the relevant information is linked together in a location-based platform.

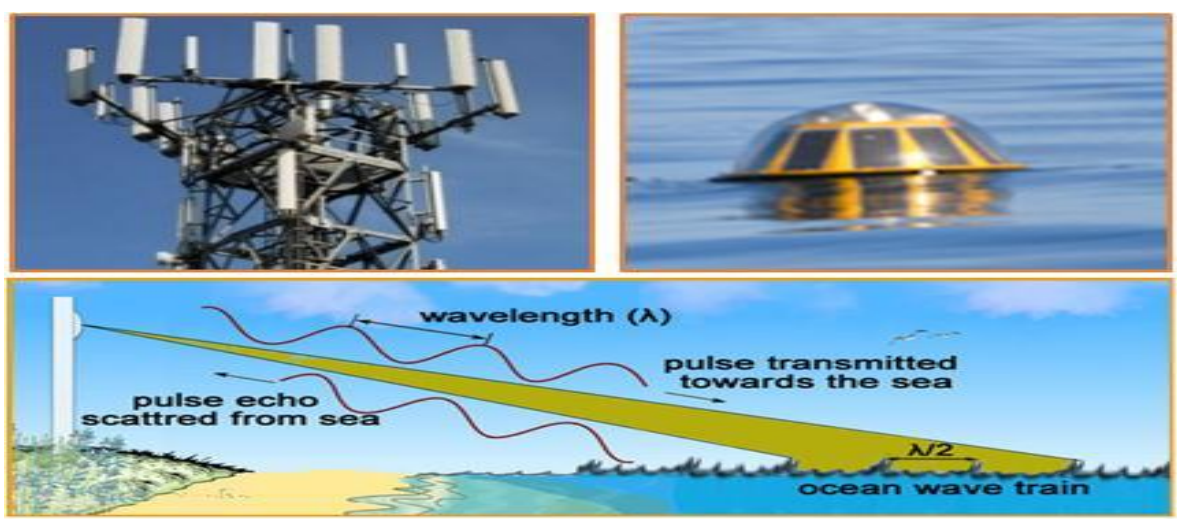

Figure 4: Network-based on sea/ground base instrumentations

Source: "Calypso Project" (Program "Italia - Malta" 2007 - 2018) 


\section{Living Labs to Test Results}

Deaths and injuries caused by debris flows, cliffs, landslides, and/or floods are often related to transportation infrastructures. Roads are the basic part of the urban texture supporting social and economic activities and represent critical infrastructure for disaster management. In addition, the transportation system is strongly linked with other kinds of networks as for examples: water supply (Lombardo et al., 2018), urban drainage, gas supply, communication infrastructure, and electrical power system. The complexity of this system is that different subjects often manage each of these infrastructures, even if they serve the same urban area and each has its own measures to react to disasters.

To reduce the impact of natural hazards on urbanized areas, as for example coastal erosion (Hurst et al., 2016; Panagou et al., 2020), cliffs, and landslides (Guida \& Valente, 2019), resident people need to identify, assess and control various factors (Adam et al., 2016) that contribute to harm the affected area. As it has been described, these factors depend on a large set of information, which is often owned by different authorities, and which ranges from sensor data, demographic data, land use data, transportations, etc. All this information needs to be integrated to allow seamless use and then they need to be processed and quickly communicated.

The main aim of the integration process is to develop a conceptual model able to support an interdisciplinary approach (Mancini et al., 2017; Calista et al., 2019) for the management of natural disasters. First responders, experts of different disciplines, and people involved in the event require access to the same data, but for different purposes.

An innovative component for the processing of data acquired by a multi-sensor platform, available for vulnerable areas and useful to characterize the regions interested by instability, for the optimization of the processing and the restitution in time of final products will be integrated. The objective is support to prevention, monitoring, and emergency activities.

The analysis of the data obtained by the multi-sensor platform allows to realize accurate studies and to extract detailed information, useful for the implementation of numerical simulations (Bilello et al., 2016; Castelli et al., 2008; Castelli \& Motta, 2013; Castelli \& Greco, 2018; Hironori et al., 2016) regarding also the disastrous events. The final goal is to have details that explain in depth the characteristic elements that can be used and that assist agencies such as national civil protection accessible in:

- Prevision and additionally avoidance stages, to ensure an appropriate land arranging;

- Emergency the executives' stage, during, and post occasion, to guarantee a brief answer of the organizations.

The experimentation for the validation of the proposed solutions developed within the project will be carried out in the southern coast of Sicily (Italy) and the islands of Malta's archipelagos. In these areas, there are centres with inestimable value, with a huge cultural tradition and historical importance.

In particular, the test sites include different coastal stretches: the coast of "Granelli" (Pachino) characterized by a thin sandy coast; the coast of "Santa Maria del Focallo" (Ispica) in South Sicily; the high stretch of coast present in "Selmun" and "Wied Il-Mielah" on the archipelagos of Malta.

Those regions are situated in geological and geomorphological settling environments (Earlie et al., 2018; Esposito et al., 2018; Pappalardo et al., 2016) that render them especially vulnerable to natural disasters (landslides, flooding, coastal erosion, and so on).

The principal goal of the research is to encourage interventions in public administrations about danger factors, mitigating strategies and contribute to the dangerous analysis of metropolitan environments, pass the "best practices" of risk management to administrations and lead to preparation, preventive and mitigating initiatives of relation to natural disasters and risk assessment steps.

This last finality, in particular, it is finalized to contribute to the achievement of specific tools for sustainable urban planning policies, especially as concern the natural events.

\section{CONCLUSION}

The southern coast of Sicily and the islands of the archipelagos of Malta are highly exposed to risks coming from the sea. Such coasts are subjected to fast erosion due to natural and anthropic causes which involve the failure of cliffs, the triggering of localized erosions, and the possibility of flooding.

In this context, the Project NEWS "Nearshore hazard monitoring and Early Warning System", (INTERREG V-A Program "Italia-Malta") has been developed. With the development of smart technologies, this research activity aimed to develop an integrated system, which includes monitoring, early warning, and mitigation of the coastal risks, specifically aiming at advising the population about the risk of flooding, littoral sand erosions, cliff failures, and at activating protection measures.

\section{LIMITATION AND STUDY FORWARD}

The limitations of the study are those characteristics of methodology that impacted and/or influenced the interpretation of the findings from the research. More robust methodological techniques are suggested for the future. 


\section{ACKNOWLEDGEMENT}

The research work has been supported by the Project NEWS "Nearshore hazard monitoring and Early Warning System", financed by the INTERREG V-A Program "Italia-Malta", Project Code C1-3.2-60, Priority Axis 3 "Protecting the environment and fostering an efficient use of resources", Specific Objective 3.2 "Mitigation of the effects of the climate changes".

This is a "free copy" and the content of this publication does not reflect the official opinion of the European Union. Responsibility for the information and views expressed lies entirely with the authors Francesco Castelli and Martina Greco.

\section{AUTHORS CONTRIBUTION}

Francesco Castelli created a conceptual and research framework and proofread the paper, and Martina Greco worked on collecting and analyzing the data.

\section{REFERENCES}

1. Adam, P., Young, R., Guza, T., William, C., O’Reilly (2016). Observations of coastal cliff base waves, sand levels, and cliff top shaking. Earth Surface Processes and Landforms, 41(11), 1564-1569. https://doi.org/10.1002/esp.3928

2. Adhikari, M., \& Srirama, S. (2019). Multi-objective accelerated particle swarm optimization with a containerbased scheduling for Internet-of-Things in cloud environment. Journal of Network and Computer Applications, 137, 35-61. https://doi.org/10.1016/j.jnca.2019.04.003

3. Ahmed, N., Firoze, A., \& Rahman, R. M. (2020). Machine learning for predicting landslide risk of Rohingya refugee camp infrastructure. Journal of Information and Telecommunication, 4(2), 175-198. https://doi.org/10.1080/24751839.2019.1704114

4. Alejano, L.R., Garcìa-Cortes, S., Garcìa-Bastante, F., \& Martìnez-Alegrìa, R. (2013). Study of a rockfall in a limy conglomerate canyon. Environmental Earth Science, 70(6), 2703-2717. https://doi.org/10.1007/s12665$\underline{013-2327-\mathrm{X}}$

5. Alessio, P., Keller, E.A. (2019). Short-term patterns and processes of coastal cliff erosion in Santa Barbara, California. Geomorphology, 353, 69-94. https://doi.org/10.1016/j.geomorph.2019.106994

6. Babu, D., \& Venkata, P. (2013). Honey bee behaviour inspired load balancing of tasks in cloud computing environments. Applied Soft Computing, 13(5), 2292-2303. https://doi.org/10.1016/j.asoc.2013.01.025

7. Barlow, J., Gilham, J., Cofrã, I.I. (2017). Kinematic analysis of sea cliff stability using UAV photogrammetry. International Journal of Remote Sensing, 38, 20-25. https://doi.org/10.1080/01431161.2016.1275061

8. Benumof, B. T., Strolatti, C. D., Seymour, R. J., \& Griggs, G. B. (2000). The relationship between incident wave energy and sea cliff erosion rates, San Diego County. Journal of Coastal Research, 16(4), 1162-1178.

9. Bezerra, M.M., Moura, D., Ferreira, O., \& Taborda, R. (2011). Influence of wave action and lithology on sea cliff mass movements in Central Algarve Coast. Journal of Coastal Research, 27(6A), 162-171. https://doi.org/10.2112/JCOASTRES-D-11-00004.1

10. Bilello, C., Greco, M., Greco, E., Madonia, N., Pirrotta, A., \& Sorce, A. (2016). A numerical model for premonitoring design of historical colonnade courtyard: The case study of Chiaramonte Palace in Palermo. The Open Construction and Building Technology Journal, 10(M3), 52-64. https://doi.org/10.2174/1874836801610010052

11. Budetta, P., Galietta, G., \& Santo, A. (2000). A methodology for the study of the relation between coastal cliff erosion and the mechanical strength of soils and rock masses. Engineering Geology, 56, 243-256. https://doi.org/10.1016/S0013-7952(99)00089-7

12. Butt, N., Whiting, S., Dethmers, K. (2016). Identifying future sea turtle conservation areas under climate change. Biological Conservation, 204, 189-196. https://doi.org/10.1016/j.biocon.2016.10.012

13. Calista, M., Mascioli, F., Menna, V. (2019). Recent geomorphological evolution and 3d numerical modelling of soft clastic rock cliffs in the mid-western Adriatic sea (Abruzzo, Italy). Geosciences, 9(7), 309-317. https://doi.org/10.3390/geosciences9070309

14. Caloiero, T., Aristodemo, F., \& Algieri Ferraro, D. (2019). Trend analysis of significant wave height and energy period in southern Italy. Theoretical and Applied Climatology, 138, 917-930. https://doi.org/10.1007/s00704-019-02879-9

15. Canora, F., Fidelibus, M., \& Spilotro, G. (2012). Coastal and inland karst morphologies driven by sea level standing: A GIS based method for their evaluation. Earth Surface Processes and Landforms, 37, 1376-1386. https://doi.org/10.1002/esp.3246

16. Castelli, F., \& Greco, M. (2018). Deep foundations and ground improvement for the slope stability of the Disueri dam (Italy). $9^{\text {th }}$ European Conference on Numerical Methods in Geotechnical Engineering NUMGE2018 (pp. 1259-1264). Taylor \& Francis. https://doi.org/10.1201/9781351003629-159

17. Castelli, F., \& Lentini, V. (2019a). Forecast models for landslides. Bulletin of Theoretical and Applied Geophysics, 60(2), 8-12.

18. Castelli, F., \& Lentini, V. (2019b). Implementation of models for decision support. Bulletin of Theoretical and 
Applied Geophysics, 60(2), 16-20.

19. Castelli, F., \& Maugeri, M. (2013). Post-earthquake analysis of a piled foundation. Journal of Geotechnical and Geoenvironmental Engineering, 139(10), 1822-1827. https://doi.org/10.1061/(ASCE)GT.19435606.0000907

20. Castelli, F., \& Motta, E. (2003). Settlement prevision of piles under vertical load. Journal of Geotechnical Engineering, 4, 183-192. https://doi.org/10.1680/geng.2003.156.4.183

21. Castelli, F., Castellano, E., Contino, F., \& Lentini, V. (2016a). A web-based GIS system for landslide risk zonation: The case of Enna area (Italy). $12^{\text {th }}$ International Symposium on Landslides - ISL2016. Taylor \& Francis. https://doi.org/10.1201/b21520-66

22. Castelli, F., Cavallaro, A., Grasso, S., Lentini, V. (2016c). Seismic microzoning from synthetic ground motion earthquake scenarios parameters: The case study of the city of Catania (Italy). Soil Dynamics and Earthquake Engineering, 88, 307-327. https://doi.org/10.1016/j.soildyn.2016.07.010

23. Castelli, F., Cavallaro, A.M., Ferraro, A., Lentini, V., \& Grasso S. (2016b). A seismic geotechnical hazard study in the ancient city of Noto (Italy). Annals of Geophysics, 61(2), 1-19.

24. Castelli, F., Lentini, V., \& Grasso, S. (2017). Recent developments for the seismic risk assessment. Bulletin of Earthquake Engineering, 15, 5093-5117. https://doi.org/10.1007/s10518-017-0163-1

25. Castelli, F., Lentini, V., Ferraro, A., \& Grasso, S. (2018). Seismic risk evaluation for the emergency management. Annals of Geophysics, 61(2), 11-22. https://doi.org/10.4401/ag-7707

26. Castelli, F., Maugeri, M., \& Mylonakis G. (2008). Numerical analysis of kinematic soil-pile interaction. Seismic Engineering International Conference: Commemorating the 1908 Messina and Reggio Calabria Earthquake, Reggio Calabria and Messina (pp. 618-625). American Institute of Physics.

27. Cavallaro, A., Castelli, F., Ferraro, A., Grasso, S., \& Lentini, V. (2018). Site response analysis for the seismic improvement of an historical and monumental building: The case study of Augusta Hangar. Bulletin of Engineering Geology and the Environment, 77, 1217-1248. https://doi.org/10.1007/s10064-017-1170-9

28. Chatzipavlis, A., Tsekouras, G.E., Trygonis, V., Velegrakis, A.F., Tsimikas, J., Rigos, A., Hasiotis, T., Salmas, C. (2019). A novel backtracking search algorithm for optimizing a neuro-fuzzy network to model beach realignment. Neural Computing \& Applications, 31,1747-1763. https://doi.org/10.1007/s00521-018-3809-2

29. Earlie, C., Masselink, G., Russell, P. (2018). The role of beach morphology on coastal cliff erosion under extreme waves. Earth Surf Process Land, 43,1213-1228. https://doi.org/10.1002/esp.4308

30. Esposito, G., Salvini. R., Matano. F., Sacchi. M., Troise. C. (2018). Evaluation of geomorphic changes and retreat rates of a coastal pyroclastic cliff in the Campi Flegrei volcanic district, southern Italy. Journal Coast Conservation, 22, 957-972. https://doi.org/10.1007/s11852-018-0621-1

31. Falcone, R., Pezzulo, G., \& Castelfranchi, C. (2003). A fuzzy approach to a belief-based trust computation. In Falcone, R., Barber, S., Korba, L. \& Singh, M. (Eds.). Trust, Reputation and Security: Theories and Practice. Springer. https://doi.org/10.1007/3-540-36609-1

32. Fazio, N., Perrotti, M., Andriani, G., Mancini, F., Rossi, P., Castagnetti, C., \& Lollino, P. (2019). A new methodological approach to assess the stability of discontinuous rocky cliffs using in-situ surveys supported by UAV-based techniques and 3-D finite element model: A case study. Engineering Geology Journal, 260, 1-15. https://doi.org/10.1016/j.enggeo.2019.105205

33. Fazio, N., Perrotti, M., Andriani, G., Mancini, F., Rossi, P., Castagnetti, C., Lollino, P. (2019). A new methodological approach to assess the stability of discontinuous rocky cliffs using in-situ surveys supported by UAV-based techniques and 3-D finite element model: a case study. Engineering Geology Journal. 260(3), 110. https://doi.org/10.1016/j.enggeo.2019.105205

34. Foti, E., Musumeci, R.E., \& Stagnitti, M. (2020). Coastal defence techniques and climate change: A review. Lincei Reports. Physical and Natural Sciences, 31, 123-128. https://doi.org/10.1007/s12210-020-00877-y

35. Gariano, S.L., Guzzetti, F. (2016). Landslides in a changing climate. Earth Science Review, 162, $227-252$. https://doi.org/10.1016/j.earscirev.2016.08.011

36. Guida, D., Valente, A. (2019). Terrestrial and marine landforms along the Cilento Coastland (Southern Italy): A Framework for landslide hazard assessment and environmental conservation. Water, 11(12), 2618-2622. https://doi.org/10.3390/w11122618

37. Hironori, M., Mark, E., Dickson, P., Kench, S. (2016). An exploratory numerical model of rocky shore profile evolution. Geomorphology, 268, 98-103. https://doi.org/10.1016/j.geomorph.2016.05.017

38. Hooke, J. (1998). Coastal defense and earth science conservation. The Geological Society of London.

39. Hurst, M.D., Rood, D.H., Ellis, M.A., Anderson, R.S., Dornbuschf, U. (2016). Recent acceleration in coastal cliff retreat rates on the south coast of Great Britain. National Academic Sciences, 113(47), 13336-13341. https://doi.org/10.1073/pnas.1613044113

40. Iannucci, R., Martino, S., Paciello, A., D’Amico, S., \& Galea, P. (2018). Engineering geological zonation of a complex landslide system through seismic ambient noise measurements at the Selmun Promontory (Malta). Geophysical Journal International, 213(2), 1146-1161. https://doi.org/10.1093/gji/ggy025

41. Jia, B., Gu, H.G., Xue, L. (2017). A basic bifurcation structure from bursting to spiking of injured nerve fibers in a two-dimensional parameter space. Cogn. Neurodyn. 11(2), 189-200. https://doi.org/10.1007/s11571-0179422-8 
42. Kumar, M., \& Sharma, S. C. (2017). Dynamic load balancing algorithm for balancing the workload among virtual machine in cloud computing. Proceedings of $7^{\text {th }}$ International Conference on Advances in Computing and Communications, ICACC-2017 (pp. 322-329). IEEE. https://doi.org/10.1016/j.procs.2017.09.141

43. Lentini, V., Castelli, F., \& Distefano, G. (2019). Management of transport infrastructures: A procedure to assess the landslide risk. Geotechnical Research for Land Protection and Development Proceedings (pp. 121128). Springer. https://doi.org/10.1007/978-3-030-21359-6_13

44. Lentini, V., Distefano, G., \& Castelli, F. (2018). Consequence analyses induced by landslides along transport infrastructures in the Enna area (South Italy). Bulletin of Engineering Geology and the Environment, 1-16.

45. Lombardo, C., Greco, M., Lentini, V., \& Castelli, F. (2018). Seismic hazard and vulnerability of three Sicilian earth dams. $16^{\text {th }}$ ECEE European Conference on Earthquake Engineering (pp. 12-17). Springer.

46. Mancini, F., Castagnetti, C., Rossi, P., Dubbini, M., Fazio, N.L., Perrotti, M., Lollino, P. (2017). An integrated procedure to assess the stability of coastal rocky cliffs: from UAV close-range photogrammetry to geomechanical finite element modeling. Remote Sensing, 9, 12-19. https://doi.org/10.3390/rs9121235

47. Panagou, T., Hasiotis, T., Velegrakis, A., Karambas, T., Oikonomou, E., Dimitriadis, C. (2020). Erosion status of a sea cliff promontory bounding an ecologically important beach. Journal of Coastal Conservation, 24(3), 110. https://doi.org/10.1007/s11852-020-00756-6

48. Pappalardo, G., Punturo, R., Mineo, S., Ortolano, G., Castelli, F. (2016). Engineering geological and petrographic characterization of migmatites belonging to the Calabria-Peloritani orogen (Southern Italy). Rock Mechanics and Rock Engineering, 49(4), 1143-1160. https://doi.org/10.1007/s00603-015-0808-9

49. Pomaro, A., Cavalieri, L., \& Lionello, P. (2017). Climatology and trends of the Adriatic Sea wind waves: analysis of a 37-year long instrumental data set. International Journal of Climatology, 37, 4237-4250. https://doi.org/10.1002/joc.5066

50. Sunamura, T. (2018). Processes of sea cliff and platform erosion. In Komar, P.D. (Ed.) Handbook of coastal processes and erosion. CRC Press.

51. Young, A.P., Carilli, J.E. (2018). Global distribution of coastal cliffs. Earth Surface Processes and Landforms, 44(6), 1309-1319. https://doi.org/10.1002/esp.4574

52. Young, A.P., Guza, R.T., O’Reilly, W.C., Burvingt, O., Flick, R.E. (2016). Observations of coastal cliff base waves, sand levels, and cliff top shaking. Earth Surface Process Landforms, 41, 1564-1573. https://doi.org/10.1002/esp.3928

53. Yusuf, M. B., Firuza, B. M., \& Khairulmaini, O. S. (2017). Variation in soil physiochemical properties at different land use sites in Northeastern Nigeria. International Journal of Applied and Physical Sciences, 3(1), 26-34. https://doi.org/10.20469/ijaps.3.50004-1 